\title{
PERSEBARAN HAMA KUTU PUTIH SINGKONG (Phenacoccus manihoti Matile- Fererro) BERBASIS SISTEM INFORMASI GEOGRAFIS DI PROVINSI GORONTALO
}

\author{
Distribution of Cassava Pink Mealybug (Phenacoccus manihoti Matile-Fererro) Based on \\ Geographic Information System in Gorontalo Province
}

\author{
Evie Adriani ${ }^{*}$, Alang', M. Darmawan ${ }^{3}$ \\ ${ }^{1,3)}$ Program Studi Agroteknologi, Fakultas Pertanian, Universitas Ichsan Gorontalo \\ ${ }^{2)}$ Program Studi Teknik Elektro, Fakultas Teknik, Universitas Ichsan Gorontalo \\ ${ }^{1 *}$ evie.adriani@gmail.com
}

\begin{abstract}
ABSTRAK
Penelitian ini bertujuan untuk mendapatkan data penyebaran populasi hama kutu putih Phenacoccus manihoti pada pertanaman singkong di Provinsi Gorontalo serta membuat Aplikasi penyebaran dari hama tersebut. Metode yang digunakan adalah metode deskriptif eksploratif dengan teknik observasi lapangan dan pembuatan aplikasi. Penelitian dilakukan pada Tahun 2021 di beberapa wilayah penghasil singkong terbesar di Provinsi Gorontalo meliputi Kabupaten Bone Bolango, Kabupaten Gorontalo dan Kota Gorontalo. Berdasarkan hasil penelitian, didapatkan data penyebaran hama kutu putih singkong Phenacoccus manihoti di Provinsi Gorontalo dan nilai intensitas serangan tertinggi pada Limboto Barat, Kabupaten Gorontalo senilai 60\%. Ditampilkan pada sebuah aplikasi untuk mengetahui keberadaan hama. Selain itu dibuat dalam pemetaan agar mampu memudahkan penyuluh dalam melakukan tindakan pengendalian hama untuk membantu petani.
\end{abstract}

\section{Kata kunci: hama kutu putih singkong, Phenacoccus manihoti, Provinsi Gorontalo, Sistem Informasi Geografis}

\begin{abstract}
The aims of this research getting data of spread population P. manihoti on cassava land in Gorontalo province and then make application the spread of pest. Methods used is exploratory descriptive methods with techniques of observation field and makin the application. The research was done 2021 in several area cassava largest producer in Gorontalo Province (Bone Bolango District, Gorontalo District and Gorontalo City). Based on the results, get the data on spread of pink cassava mealybug P. manihoti in Gorontalo Province and the higest attack intensity value was in West Limboto, Gorontalo District approx. 60\%. Displayed on an application to find out the presence of pests. In addition, it is made in the mapping to be able to make it easier for extension workers to carry out pest control actions to help farmers.
\end{abstract}

Keywords: pink cassava mealybug, Phenacoccus manihoti, Gorontalo Province, geographic information system

\section{PENDAHULUAN}

Potensi nilai ekonomi dan sosial singkong merupakan bahan pangan masa depan yang berdaya guna serta bahan baku berbagai industri dan pakan ternak. Singkong merupakan tanaman yang keberadaannya di Indonesia sebagai penghasil karbohidrat terbesar ketiga setelah padi dan jagung. Singkong merupakan tanaman pertanian yang berasal dari Amerika Selatan (Thamrin dkk., 2013). Gorontalo merupakan wilayah penghasil singkong dikarenakan sebagian makanan olahan lokal berasal dari singkong. 
Perbal: Jurnal Pertanian Berkelanjutan

Fakultas Pertanian Universitas Cokroaminoto Palopo

Maka dari itu diperlukan upaya agar produksi singkong di Gorontalo tidak terdapat hambatan dan dapat mengalami peningkatan. Salah satu hambatan dalam produksi singkong yaitu adanya keberadaa hama utama tanaman singkong yaitu Phenacoccus manihoti (Rauf, 2014). Serangan hama P.manihoti pada tanaman singkong menyebabkan tanaman kerdil, daun menguning, berguguran, Bunchy top, dan ruas batang memendek, serta batang singkong menjadi lembek (Abduchalek, 2017).

Penelitian ini bertujuan untuk mendapatkan data penyebaran populasi hama kutu putih Phenacoccus manihoti pada pertanaman singkong di Provinsi Gorontalo serta membuat Aplikasi penyebaran dari hama tersebut. Luaran dari penelitian ini yaitu untuk mendapatkan data penyebaran hama kutu putih singkong Phenacoccus manihoti di Provinsi Gorontalo dengan membuatkan sebuah aplikasi untuk mengetahui keberadaan dari hama tersebut. Selain itu dibuat dalam pemetaan agar mampu memudahkan penyuluh dalam melakukan Tindakan pengendalian hama untuk membantu petani dan perusahaan penghasil singkong.

\section{METODE PENELITIAN}

Metode yang digunakan adalah metode deskriptif eksploratif dengan teknik observasi lapangan dan pembuatan aplikasi. Penelitian dilakukan mulai Bulan Februari hingga November Tahun 2021 di beberapa wilayah penghasil singkong terbesar di Provinsi Gorontalo. Kabupaten Bone Bolango termasuk penghasil singkong terbesar di Provinsi Gorontalo yang meliputi beberapa Kecamatan.

\section{Penentuan Lokasi Pengamatan}

Penentuan lokasi ini dilaksanakan pada 2021, bertujuan untuk menentukan daerah yang akan diamati. Lokasi tempat pengambilan sampel dilakukan di Gorontalo. Masing-masing ditentukan titik lokasi pengambilan sampel dengan ukuran luas setiap titik lokasi/pertanaman singkong mulai dari 1 are hingga yang luasnya 1 ha. Jarak antar titik lokasi minimal $1 \mathrm{~km}$ untuk memastikan perbedaan kelimpahan kutu putih. Posisi geografi setiap titik lokasi pengamatan dicatat menggunakan GPS.

\section{Parameter Pengamatan}

Parameter yang diamati meliputi: Kerapatan populasi dan intensitas kerusakan. Metode yang digunakan untuk pengambilan data hama kutu putih (Phenacoccus manihoti) adalah simple random sampling yaitu sampel diambil dari satu petak lahan dan ditentukan lima area tanaman. Masing- 
masing area diwakili 5 tanaman dengan menggunakan pola diagonal sehingga didapatkan 25 sampel tanaman. Jumlah populasi tanaman masing-masing lokasi pengambilan sampel sekurang-kurangnya 25 tanaman.

Pengukuran intensitas kerusakan tanaman dilaksanakan setelah selesai melakukan pengamatan kerapatan populasi. Penetapan intensitas kerusakan tanaman dilihat dari gejala yang terlihat pada tanaman seperti bunchy top yaitu bagian pucuk dari tanaman singkong tidak bisa berkembang lagi atau menghambat proses fotosintesis dikarenakan kutu putih menghisap jaringan floem dari daun singkong dan distorsi batang ialah serangan yang dilakukan oleh hama kutu putih P.manihoti pada batang singkong sehingga terjadi gangguan pada pertumbuhan batang singkong.

\section{Tahap Analisis Sistem}

Metode yang digunakan dalam analisis sistem adalah metode rekayasa perangkat lunak dengan model prototipe (Prototyping Model). Model ini bertujuan untuk membuat ptototipe dari perangkat lunak yang akan dibuat. Model prototipe dapat digunakan untuk memastikan efisiensi algoritma dan kemampuan penyesuaian dari Sistem Operasi dan bentuk-bentuk yang harus dilakukan terhadap antarmuka suatu sistem. Model Prototipe dapat dilihat pada gambar berikut ini.

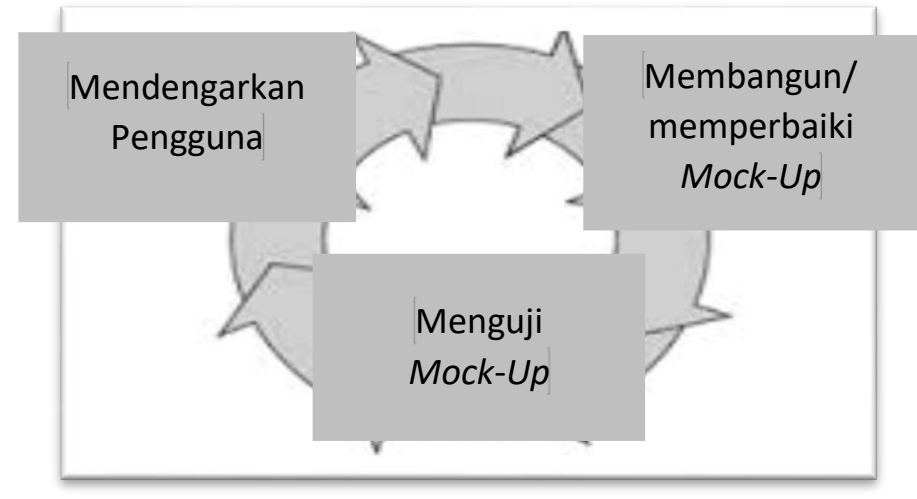

Gambar 1. Ilustrasi Model Prototipe

Sumber: Rosa \& Shalahuddin, 2013

Tahapan Pembuatan Sistem

Dalam pembuatan sistem dengan menggunakan metode prototipe ini yaitu:
1. Pengumpulan data dan menganalisis kebutuhan

2. Membangun sebuah prototipe

3. Evaluasi oleh konsumen atas prototipe 
Perbal: Jurnal Pertanian Berkelanjutan

Fakultas Pertanian Universitas Cokroaminoto Palopo

4. Perubahan rancangan dan prototipe

5. Apabila prototipe yang dibangun tidak sesuai denan kebutuhan maka ulangi langkah 5, dan

6. Apabila sudah sesuai dengan kebutuhan terhadap prototipe yang di bangun, maka pembuatan dan pengembangan produk segera dapat dimulai.

\section{Tahapan Pengujian Sistem}

Pengujian yang dilakukan dengan dua teknik pengujian, yaitu;

a. White Box

Pengujian WhiteBox ini dengan membuat bagan alir program, listing program, grafik alir, pengujian basispath serta perhitungan Ciclomatic Complexity.

b. Black Box

Menguji antarmuka sistem, apakah sebuah sistem setelah diberikan ke pengguna dapat dioperasikan atau tidak.

Tujuan dari pengujian adalah untuk mendeteksi:

1) Kesalahan bahasa

2) Kesalahan waktu proses

3) Kesalahan logika

\section{Tahapan Implementasi}

Dalam implementasi perangkat lunak tentunya dibutuhkan dukungan perangkat lunak dan perangkat keras yang baik agar mendukung saat penulisan program.

\section{HASIL DAN PEMBAHASAN}

Dalam proses pembuatan Sistem Informasi Geografis pemetaan hama kutu putih P. manihoti di Provinsi Gorontalo. Terdapat dua kebutuhan data yang digunakan dalam proses pembuatan aplikasi diantaranya data spasial dan data nonspasial. Data spasial memuat tentang lokasi berdasarkan posisi geografis objek dalam Bumi dengan menggunakan koordinat. Data tersebut diperoleh dengan menggunakan fasilitas dari Google maps (Tabel 1).

Data non-spasial merupakan data yang memuat karakteristik atau keterangan dari suatu objek yang terdapat dalam peta tetapi tidak berkaitan dengan posisi geografi objek. Adapun data non-spasial dari penelitian ini yaitu data kerapatan populasi dan intensitas serangan hama kutu putih $P$. manihoti. Berdasarkan hasil pengamatan, seluruh lokasi pengamatan ditemukan populasi $P$. manihoti. Lokasi yang paling tinggi terdapat populasi kutu putih $P$. manihoti yaitu di Desa Hutabohu, Kecamatan Limboto Barat, Kabupaten Gorontalo. 
Tabel 1. Data spasial hama P. manihoti di Provinsi Gorontalo

\begin{tabular}{|c|c|c|c|c|c|}
\hline No & Lahan & Alamat & Kabupaten & Latitude & Longitude \\
\hline 1 & Lahan 1 & Butu, Tilong Kabila & Bone Bolango & 0.5618119 & 123.1369573 \\
\hline 2 & Lahan 2 & Butu, Tilong Kabila & Bone Bolango & 0.5594532 & 123.1347667 \\
\hline 3 & Lahan 3 & Butu, Tilong Kabila & Bone Bolango & 0.5612648 & 123.1360953 \\
\hline 4 & Lahan 4 & Butu, Tilong Kabila & Bone Bolango & 0.5613682 & 123.136245 \\
\hline 5 & Lahan 5 & Iloheluma, Tilong kabila & Bone Bolango & 0.5638751 & 123.1265412 \\
\hline 6 & Lahan 6 & Iloheluma, Tilong kabila & Bone Bolango & 0.5638751 & 123.1265412 \\
\hline 7 & Lahan 7 & Iloheluma, Tilong kabila & Bone Bolango & 0.5661558 & 123.1269518 \\
\hline 8 & Lahan 8 & Moutong, Tilong Kabila & Kabupaten Gorontalo & 0.5559354 & 123.1381543 \\
\hline 9 & Lahan 9 & Huluduotamo, Suwawa & Bone Bolango & 0.5514452 & 123.1375041 \\
\hline 10 & Lahan 10 & Bongoime, Tilong Kabila & Bone Bolango & 0.5738687 & 123.1190277 \\
\hline 11 & Lahan 11 & $\begin{array}{l}\text { Jl. Raya Eyato, Buladu, } \\
\text { Kota Barat }\end{array}$ & Kota Gorontalo & 0.5503837 & 123.0322927 \\
\hline 12 & Lahan 12 & $\begin{array}{l}\text { Jl. Beluntas, Tenilo, Kota } \\
\text { Barat }\end{array}$ & Kota Gorontalo & 0.5413791 & 123.042841 \\
\hline 13 & Lahan 13 & $\begin{array}{l}\text { Jl. Abdul Gandi Pajuhi, } \\
\text { Dumati, Telaga Biru }\end{array}$ & Kabupaten Gorontalo & 0.6068235 & 123.0421063 \\
\hline 14 & Lahan 14 & Tuladenggi, Telaga Biru & Kabupaten Gorontalo & 0.6082474 & 123.0354663 \\
\hline 15 & Lahan 15 & $\begin{array}{l}\text { Belakang Kantor Camat, } \\
\text { Tinelo, Telaga Biru }\end{array}$ & Kabupaten Gorontalo & 0.6126694 & 123.031692 \\
\hline 16 & Lahan 16 & $\begin{array}{l}\text { Jl. Adam Poliyama, } \\
\text { Tinelo, Telaga Biru }\end{array}$ & Kabupaten Gorontalo & 0.6047107 & 123.0263989 \\
\hline 17 & Lahan 17 & Timuato, Telaga Biru & Kabupaten Gorontalo & 0.6172053 & 123.0228686 \\
\hline 18 & Lahan 18 & $\begin{array}{l}\text { Jl. Abdul A.Wahab, } \\
\text { Ulapato A, Telaga Biru }\end{array}$ & Kabupaten Gorontalo & 0.6128087 & 123.0217376 \\
\hline 19 & Lahan 19 & $\begin{array}{l}\text { Pentadio Barat, Telaga } \\
\text { Biru }\end{array}$ & Kabupaten Gorontalo & 0.6276413 & 123.0102096 \\
\hline 20 & Lahan 20 & $\begin{array}{l}\text { J1. Adam Hoesa, Pentadio } \\
\text { Timur, Telaga Biru }\end{array}$ & Kabupaten Gorontalo & 0.6283064 & 123.0101138 \\
\hline 21 & Lahan 21 & $\begin{array}{l}\text { Jl. Prof.Dr.H. Mansoer } \\
\text { Pateda No.212, Pentadio } \\
\text { Timur, Telaga Biru }\end{array}$ & Kabupaten Gorontalo & 0.6236085 & 123.0155893 \\
\hline 22 & Lahan 22 & $\begin{array}{l}\text { Jl. Adam Hoesa, } \\
\text { Talumelito, Telaga Biru }\end{array}$ & Kabupaten Gorontalo & 0.6298834 & 123.0095277 \\
\hline 23 & Lahan 23 & $\begin{array}{l}\text { Jl. Adam Hoesa, } \\
\text { Talumelito, Telaga Biru }\end{array}$ & Kabupaten Gorontalo & 0.6298834 & 123.0095277 \\
\hline 24 & Lahan 24 & Hutuo, Limboto & Kabupaten Gorontalo & 0.6284064 & 123.0040952 \\
\hline 25 & Lahan 25 & $\begin{array}{l}\text { Jl. Nuna Mutaha, } \\
\text { Kayubulan, Limboto }\end{array}$ & Kabupaten Gorontalo & 0.6088873 & 122.9798382 \\
\hline 26 & Lahan 26 & $\begin{array}{l}\text { Jl. Brig. Jend. Piola Isa, } \\
\text { Bolihuangga, Limboto }\end{array}$ & Kabupaten Gorontalo & 0.6233775 & 122.9696886 \\
\hline 27 & Lahan 27 & Hunggaluwa, Limboto & Kabupaten Gorontalo & 0.6254277 & 122.9717917 \\
\hline 28 & Lahan 28 & $\begin{array}{l}\text { J1. Trans Sulawesi, } \\
\text { Tenilo, Limboto }\end{array}$ & Kabupaten Gorontalo & 0.6226533 & 122.9580122 \\
\hline 29 & Lahan 29 & Hutabohu, Limboto Barat & Kabupaten Gorontalo & 0.6066122 & 122.9364275 \\
\hline 30 & Lahan 30 & Dungaliyo, Bongomeme & Kabupaten Gorontalo & 0.6019219 & 122.8995666 \\
\hline
\end{tabular}

Sumber: Data primer setelah diolah, tahun 2021 
Pada wilayah tersebut, seluruh titik sampel tanaman yang diamati ditemukan adanya koloni kutu putih $P$. manihoti. Penelitian ini menunjukkan hama kutu putih P. manihoti telah menyebar di Provinsi Gorontalo. Dari 30 lokasi pengamatan, semua lokasi tersebut terdapat populasi hama $P$. manihoti yang ditemukan di dua Kabupaten dan satu Kota, yaitu Kabupaten Bone Bolango, Kabupaten Gorontalo dan Kota Gorontalo.

Penelitian penyebaran kutu putih $P$. manihoti sebelumnya telah dilakukan di Pulau Jawa, Lampung dan Lombok. Di Pulau Jawa, ditemukan pada 22 lokasi yaitu Jawa Barat, Jawa Tengah dan Jawa Timur (Abduchalek, 2017). Di Lampung, ditemukan pada lima Kecamatan di Lampung Tengah, Lampung Timur dan Lampung Selatan (Sidarlin dkk., 2020). Hama P. manihoti sudah menyebar di Pulau Lombok dan ditemukan hampir disemua
Kabupaten. Dari 33 lokasi pengamatan, terdapat 26 lokasi yang menunjukkan keberadaan hama P. manihoti meliputi Kota Mataram, Kabupaten Lombok Barat, Kabupaten Lombok Timur, Kabupaten Lombok Tengah, dan Kabupaten Lombok Utara (Awan dkk., 2018). Selain itu, hasil penelitian lainnya dari Rebu dan Rauf (2018), penelitian survei sebaran hama di Kabupaten Kupang menunjukkan hasil bahwa dari 10 titik lokasi survey dan 5 kecamatan di Kabupaten Kupang, $P$. manihoti ditemukan hampir disemua wilayah pengamatan dengan gejala bunchy top, buku pendek, dan daun gugur sehingga menyebabkan pertumbuhan tanaman menjadi terhambat. Keberadaan P. manihoti pada tanaman singkong ditandai adanya koloni kutu putih yang terdiri dari nimfa yang berwarna merah muda serta imago dan ovizak yang berwarna putih pada pucuk tanaman singkong (Gambar 2).

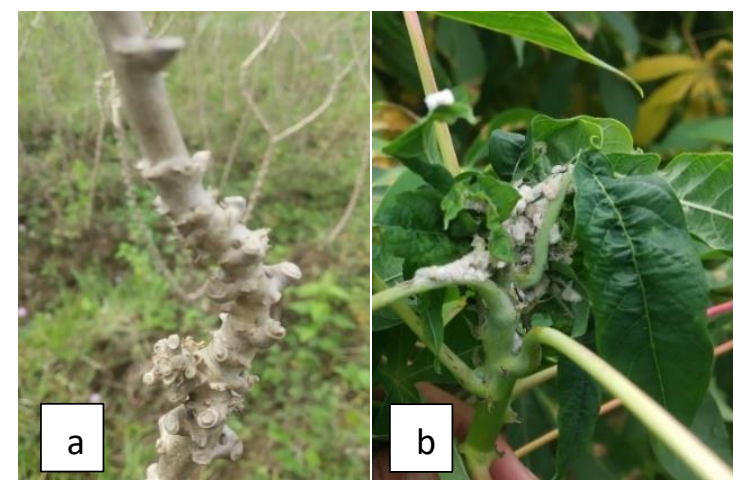

Gambar 2. Gejala kutu putih singkong $P$. manihoti (a. Distorsi batang, b. Bunchy top) 
Berdasarkan hasil penelitian, nilai kerapatan populasi dan intensitas serangan dari hama kutu putih $P$. manihoti tidak berbeda jauh antar tiap lokasi pengamatan (Tabel 2). Kerapatan populasi tertinggi terdapat pada lahan ke 29 yaitu di Kecamatan Limboto Barat, Kabupaten Gorontalo dengan 5 gejala bunchy top dan distorsi batang dan intensitas serangan sebesar $60 \%$. Hasil penelitian tersebut serupa dengan penelitian sebelumnya pada 2020 di Provinsi Lampung yaitu Populasi kutu putih di Lampung Tengah sebesar 0,68 indiv./ 3 daun tidak berbeda dengan populasi kutu putih di Lampung Timur yaitu sebesar 3,26 indiv./3 daun. Intensitas serangan tertinggi pada Lampung Timur yaitu 59\% (Sidarlin dkk., 2020).

Tabel 2. Data non-spasial kerapatan populasi dan intensitas serangan hama P. manihoti di Provinsi Gorontalo

\begin{tabular}{|c|c|c|c|c|c|}
\hline No. & Kabupaten & Kecamatan & Desa & $\begin{array}{l}\text { Kerapatan Populasi } \\
\text { (Bunchy top) }\end{array}$ & $\begin{array}{l}\text { Intensitas } \\
\text { Serangan }(\%)\end{array}$ \\
\hline 1 & Bone Bolango & Tilongkabila & Butu & 3 & 30 \\
\hline 2 & Bone Bolango & Tilongkabila & Butu & 2 & 20 \\
\hline 3 & Bone Bolango & Tilongkabila & Butu & 2 & 10 \\
\hline 4 & Bone Bolango & Tilongkabila & Butu & 4 & 60 \\
\hline 5 & Bone Bolango & Tilongkabila & Iloheluma & 4 & 50 \\
\hline 6 & Bone Bolango & Tilongkabila & Iloheluma & 4 & 50 \\
\hline 7 & Bone Bolango & Tilongkabila & Iloheluma & 2 & 20 \\
\hline 8 & Bone Bolango & Tilongkabila & Moutong & 3 & 20 \\
\hline 9 & Bone Bolango & Suwawa & Huluduotamo & 3 & 20 \\
\hline 10 & Bone Bolango & Suwawa & Bongoime & 3 & 40 \\
\hline 11 & Bone Bolango & Suwawa & Buladu & 4 & 40 \\
\hline 12 & Kota Gorontalo & Kota Barat & Tenilo & 3 & 50 \\
\hline 13 & Gorontalo & Telaga Biru & Dumati & 4 & 40 \\
\hline 14 & Gorontalo & Telaga Biru & Tuladenggi & 3 & 20 \\
\hline 15 & Gorontalo & Telaga Biru & Tinelo & 2 & 10 \\
\hline 16 & Gorontalo & Telaga Biru & Tinelo & 4 & 50 \\
\hline 17 & Gorontalo & Limboto & Timuato & 3 & 30 \\
\hline 18 & Gorontalo & Telaga Biru & Ulapato & 3 & 30 \\
\hline 19 & Gorontalo & Telaga Biru & Pentadio Barat & 2 & 10 \\
\hline 20 & Gorontalo & Telaga Biru & Pentadio Timur & 3 & 30 \\
\hline 21 & Gorontalo & Telaga Biru & Pentadio Timur & 4 & 50 \\
\hline 22 & Gorontalo & Telaga Biru & Talumelito & 4 & 40 \\
\hline 23 & Gorontalo & Telaga Biru & Talumelito & 4 & 40 \\
\hline 24 & Gorontalo & Limboto & Hutuo & 3 & 30 \\
\hline 25 & Gorontalo & Limboto & Kayu Bulan & 1 & 5 \\
\hline 26 & Gorontalo & Limboto & Bolihuangga & 3 & 50 \\
\hline 27 & Gorontalo & Limboto & Hunggaluwa & 4 & 40 \\
\hline
\end{tabular}


Perbal: Jurnal Pertanian Berkelanjutan

Fakultas Pertanian Universitas Cokroaminoto Palopo

28 Kota Gorontalo Kota Barat $\quad$ Tenilo $\quad 3 \quad 20$

29 Gorontalo Limboto Barat Hutabohu $\quad 5 \quad 60$

30 Gorontalo Dungaliyo Dungaliyo $\quad 4 \quad 50$

Sumber: Data primer setelah diolah, tahun 2021

Database yang dirancang untuk Berikut gambar rancangan database yang pembuatan aplikasi sebanyak 3 tabel yaitu telah dibuat.

lahan singkong, Kabupaten, dan admin.

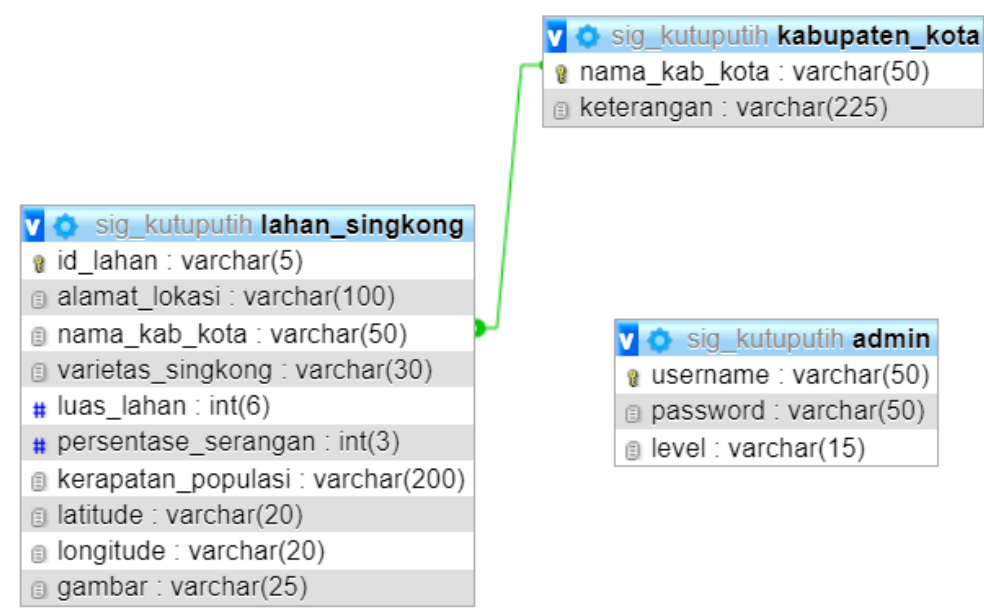

Gambar 3. Rancangan database

Desain interface data lahan singkong penginputan data lahan singkong ke dalam Armada berfungsi untuk tampilan sistem.

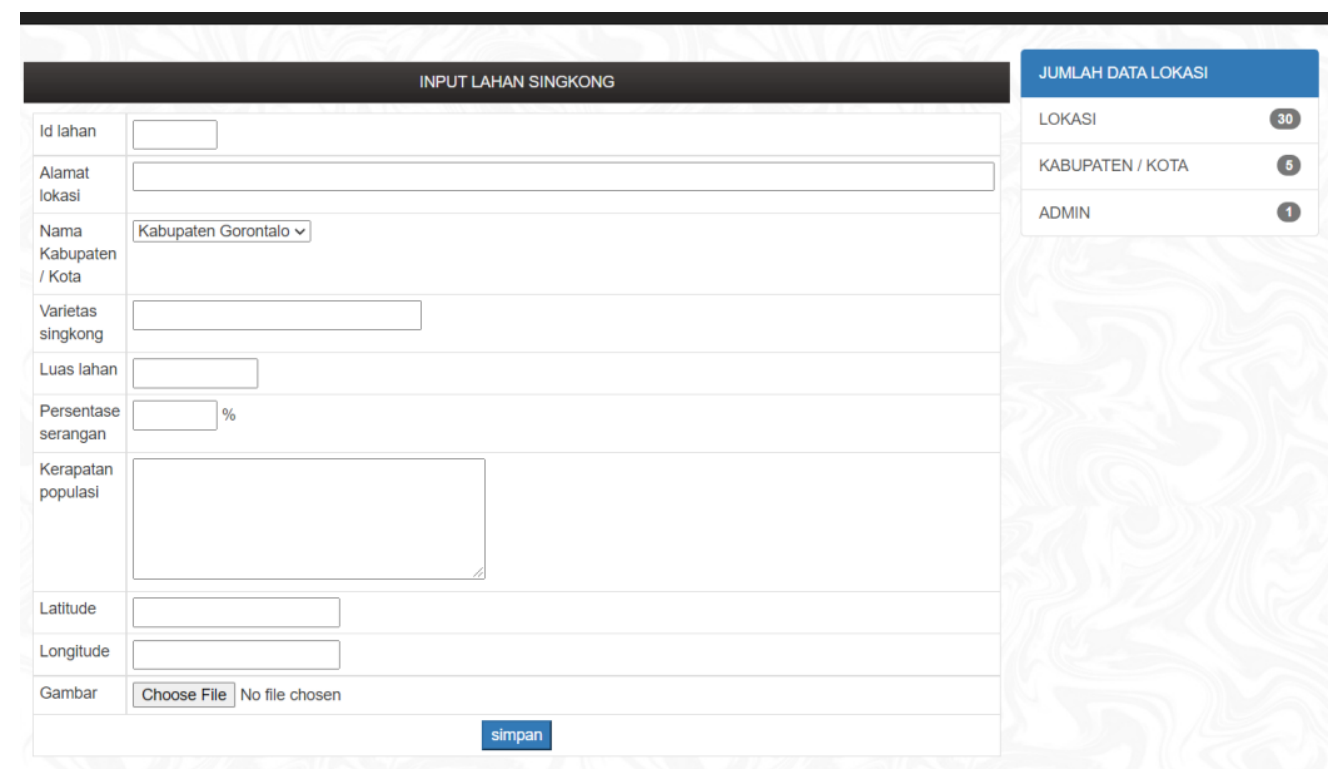

Gambar 4. Desain interface data lahan singkong 
Daftar lahan singkong berfungsi untuk hama kutu putih. melihat data lahan singkong yang terkena

\begin{tabular}{|c|c|c|c|c|c|c|c|c|c|c|}
\hline \multicolumn{11}{|c|}{ DAFTAR LAHAN SINGKONG } \\
\hline $\begin{array}{c}\text { Id } \\
\text { lahan }\end{array}$ & $\begin{array}{l}\text { Alamat } \\
\text { lokasi }\end{array}$ & $\begin{array}{c}\text { Nama kab } \\
\text { kota }\end{array}$ & $\begin{array}{c}\text { Varietas } \\
\text { singkong }\end{array}$ & $\begin{array}{l}\text { Luas } \\
\text { lahan }\end{array}$ & $\begin{array}{c}\text { Persentase } \\
\text { serangan }\end{array}$ & $\begin{array}{c}\text { Kerapatan } \\
\text { populasi }\end{array}$ & Latitude & Longitude & Gambar & (ब) \\
\hline LS001 & $\begin{array}{l}\text { Butu, Tilong } \\
\text { Kabila }\end{array}$ & $\begin{array}{l}\text { Bone } \\
\text { Bolango }\end{array}$ & Mentega & 1 & $30 \%$ & $\begin{array}{l}\text { Skoring } 3 \\
\text { dari } 5 \text { Unit } \\
\text { Sampel } \\
\text { (Umur } \\
\text { singkong } \\
10 \text { Bulan) }\end{array}$ & 0.5618119 & 123.1369573 & LS001.jpg & $*$ \\
\hline LSO02 & $\begin{array}{l}\text { Butu, Tilong } \\
\text { Kabila }\end{array}$ & $\begin{array}{l}\text { Bone } \\
\text { Bolango }\end{array}$ & Mentega & 2 & $20 \%$ & $\begin{array}{l}\text { Skoring } 2 \\
\text { dari } 5 \text { Unit } \\
\text { Sampel } \\
\text { (Umur } \\
\text { singkong } 8 \\
\text { Bulan) }\end{array}$ & 0.5594532 & 123.1347667 & LS002.jpg & * \\
\hline LS003 & $\begin{array}{l}\text { Butu, Tilong } \\
\text { Kabila }\end{array}$ & $\begin{array}{l}\text { Bone } \\
\text { Bolango }\end{array}$ & Mentega & 1 & $10 \%$ & $\begin{array}{l}\text { Skoring } 2 \\
\text { dari } 5 \text { Unit } \\
\text { Sampel } \\
\text { (Umur } \\
\text { singkong } \\
10 \text { Bulan) }\end{array}$ & 0.5612648 & 123.1360953 & LS003.jpg & * \\
\hline
\end{tabular}

Gambar 5. Daftar lahan singkong

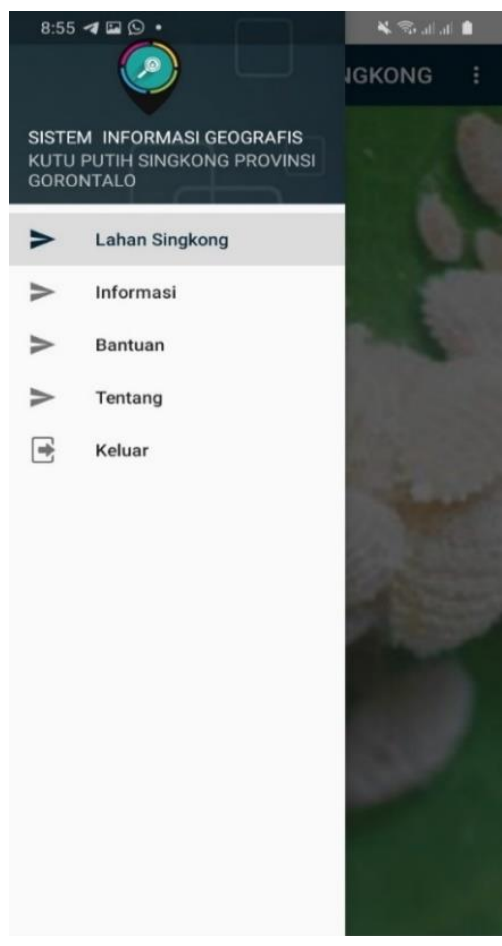

Gambar 6. Menu utama pada sistem informasi geografis

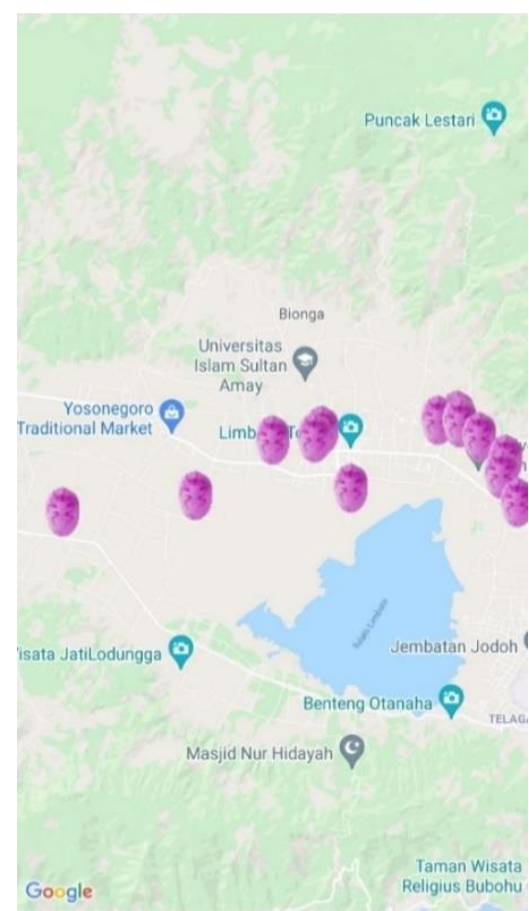

Gambar 7. Sistem informasi geografis lahan singkong yang terserang hama kutu putih 
Perbal: Jurnal Pertanian Berkelanjutan

Fakultas Pertanian Universitas Cokroaminoto Palopo

Gambar 6 dan 7 merupakan tampilan pada aplikasi sistem informasi geografis lahan singkong yang terserang hama $P$. manihoti. Hal ini serupa dengan hasil penelitian yang dilakukan oleh Husain dan Adriani (2020), penelitian ini berhasil menganalisis dan menentukan zonasi sebaran hama kutu kebul pada pertanaman cabai rawit berkat sistem informasi geografis serta memberikan data berupa klasifikasi lahan penyebaran hama kutu kebul sehingga dinas yang terkait dapat menyusun strategi pengendalian hama kutu kebul secara spasial. Aplikasi ini juga telah melalui dua metode pengujian yaitu whitebox dengan hasil bahwa aplikasi ini telah layak untuk diimplementasikan.

\section{KESIMPULAN DAN SARAN}

Berdasarkan hasil penelitian, nilai kerapatan populasi dan intensitas serangan dari hama kutu putih $P$. manihoti tidak berbeda jauh antar tiap lokasi pengamatan. Kerapatan populasi tertinggi terdapat pada lahan ke 29 yaitu di Kecamatan Limboto Barat, Kabupaten Gorontalo dengan 5 gejala bunchy top dan distorsi batang dan intensitas serangan sebesar $60 \%$.

Berdasarkan hasil dari perancangan Sistem Informasi Geografis (SIG) untuk persebaran hama $P$. manihoti di Provinsi Gorontalo, maka dapat diambil kesimpulan bahwa penggunaan sistem pemetaan yang merupakan model permukaan bumi dengan lapisan Google Map sebagai referensi peta dasar dapat memetakan serangan hama $P$. manihoti pada tanaman singkong. Data pendukung yang telah dicantumkan dalam bentuk data spasial dan data non-spasial, sehingga sistem dapat dijadikan salah satu alternatif yang dapat membantu dalam memantau persebaran hama pada pertanaman singkong.

\section{UCAPAN TERIMA KASIH DAN PENGHARGAAN}

Peneliti mengucapkan terimakasih kepada Lembaga Penelitian Universitas Ichsan Gorontalo dan Kementrian Riset, Teknologi dan Badan Riset dan Inovasi Nasional atas dukungan yang diberikan kepada peneliti berupa bantuan dana penelitian.

\section{DAFTAR PUSTAKA}

Abduchalek, B., Rauf, A. \& Pudjianto. (2017). Kutu putih Singkong, Phenacoccus manihoti Matile-Ferrero (Hemiptera: Pseudococcidae): Persebaran geografi di Pulau Jawa dan rintisan pengendalian hayati. J. HPT Tropika. Vol. 17(1): 1-8.

Awan, H. (2018). Distribusi dan Karakteristik Hama Kutu Putih Ubi Kayu (Phenacoccus manihoti) di Pulau Lombok. [Skripsi]. Fakultas Pertanian. Universitas Mataram. Mataram.

Husain, H. \& Adriani, E. (2020). Sistem Informasi Geografis Penyebaran Kutu Kebul pada Tanaman Cabai Berbasis Android di Provinsi Gorontalo. Jurnal 
Teknologi Informasi Indonesia. Vol. 5, No. 2.

Rauf, A. (2014). Invasi kutu putih Phenacoccus manihoti. Di dalam: Seminar Kutu putih vs Parasitoid: Pengelolaan Hama Asing Invasif Berbasis Ekologi. Bogor 24 September 2014.

Rebu, J.U. \& Rauf, A. (2018). Survey Hama Eksotik Phenacoccus manihoti MatileFerrero (Hemiptera: Pseudococcidae) pada Tanaman Singkong di Kabupaten Kupang. Prosiding Seminar Nasional Pertanian Ke V, Pengelolaan Pertanian Lahan Kering Berkelanjutan untuk Menunjang Kedaulatan Pangan.

Rosa, A., \& Shalahuddin, M. (2013). Rekayasa Perangkat Lunak. Informatika Bandung. Bandung.

Sidarlin, I.G. Swibawa, A.M. Hariri, F.X. Susilo. (2020). Tingkat Serangan dan Populasi Hama Kutu Putih pada Beberapa Pertanaman Ubi Kayu (Manihot esculanta Crantz) di Lampung. $J$. Agrotek Tropika. Vol. 8(2): 375-381.

Thamrin M., Mardhiyah A., Marpaung S. E. (2013). Analisis Usahatani Ubi Kayu (Manihot utilissima). Jurnal Agrium. Vol. 18, No.1. 